\title{
Liquefied Natural Gas for Civil Aviation
}

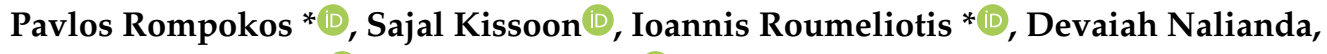 \\ Theoklis Nikolaidis ${ }^{-1}$ and Andrew Rolt $(0)$ \\ Propulsion Engineering Center, School of Aerospace, Transport and Manufacturing, Cranfield University, \\ Building 52, College Rd, Cranfield, Wharley End, Bedford MK43 0AL, UK; S.Kissoon@cranfield.ac.uk (S.K.); \\ devaiah.nalianda@cranfield.ac.uk (D.N.); t.nikolaidis@cranfield.ac.uk (T.N.); a.rolt@cranfield.ac.uk (A.R.) \\ * Correspondence: Pavlos.Rompokos@cranfield.ac.uk (P.R.); I.Roumeliotis@cranfield.ac.uk (I.R.)
}

Received: 23 October 2020; Accepted: 9 November 2020; Published: 13 November 2020

\begin{abstract}
The growth in air transport and the ambitious targets in emission reductions set by advisory agencies are some of the driving factors behind research towards new fuels for aviation. Liquefied Natural Gas (LNG) could be both environmentally and economically beneficial. However, its implementation in aviation has technical challenges that needs to be quantified. This paper assesses the application of LNG in civil aviation using an integrated simulation and design framework, including Cranfield University's aircraft performance tool, Orion, and engine performance simulation tool Turbomatch, integrated with an LNG tank sizing module and an aircraft weight estimation module. Changes in tank design, natural gas composition, airframe changes, and propulsion system performance are assessed. The performance benefits are quantified against a Boeing 737-800 aircraft. Overall, LNG conversion leads to a slightly heavier aircraft in terms of the operating weight empty (OWE) and maximum take-off weight (MTOW). The converted aircraft has a slightly reduced range compared to the conventional aircraft when the maximum payload is considered. Compared to a conventional aircraft, the results indicate that although the energy consumption is increased in the case of LNG, the mission fuel mass is decreased and $\mathrm{CO}_{2}$ emissions are reduced by more than $15 \%$. These benefits come with a significant reduction in fuel cost per passenger, highlighting the potential benefits of adopting LNG for aviation.
\end{abstract}

Keywords: liquefied natural gas; LNG; civil aviation; engine performance; mission analysis; short-range aircraft; $\mathrm{CO}_{2}$ emission reduction

\section{Introduction}

The Earth is reported to have lost 28 trillion tons of ice since 1994 [1]. This finding coincides with a worst-case scenario predicted by the United Nation's Intergovernmental Panel on Climate Change (IPCC). This massive response to the rise in global temperatures only accentuates the immediate need for action. According to the Air Transport Action Group [2], the global aviation industry produces around $2 \%$ of all human-induced $\mathrm{CO}_{2}$ emissions, which constitutes approximately $12 \%$ of $\mathrm{CO}_{2}$ emissions within the transport sector. These figures are bound to grow with projected increases in passenger demand for air travel. In approximately 10 years, the global fleet is expected to grow by $42 \%[3]$.

In an attempt to curb greenhouse gas emissions and protect the environment, the Advisory Council for Aviation Research and Innovation in Europe (ACARE), through FlightPath2050 [4], set up ambitious goals for the aviation industry for the year 2050. Specifically, a $75 \%$ reduction in $\mathrm{CO}_{2}$ emissions per passenger $\mathrm{km}, 90 \%$ reduction in NOx emissions, and a $65 \%$ reduction in perceived noise compared to a typical new aircraft in 2000 are targeted. To achieve these goals, improvements at the system level are required, encompassing improvements to the airframe, engine, and operations in a synergistic manner. 
Engine development is estimated to be capable of achieving a 20\% reduction in fuel burn [5]. For example, the UltraFan ${ }^{\circledR}$ engine (Rolls Royce, West Sussex, UK), with an ultra-high bypass ratio design, should achieve a $25 \%$ improvement in fuel burn compared to Trent $772 \mathrm{~B}$ engine, which is a representative year 2000 engine [6]. However, the fan diameter is limited by the space available under the wing, installed drag, and weight. In terms of airframe development, a radically new configuration deviating away from the traditional tube-and-wing design is required to achieve a significant reduction in fuel consumption. The blended wing body is one such example developed by NASA, which achieves improved fuel benefits due to the superior lift-to-drag ratio, improved payload capability, and lower noise level. Additionally, superior air traffic management and operations, which could optimize flight trajectories and reduce ground idling times, could further decrease unnecessary fuel burn [7]. However, these improvements can only cut fuel consumption to a certain extent, and only reduce the amount of $\mathrm{CO}_{2}$ generated pro rata to the fuel burned. In order to achieve up to a $75 \%$ reduction in emission of carbon, alternative fuels may be required, as discussed in [4].

The choice of an aviation fuel is dictated by various criteria, which are mainly dependent on availability, emissions, price, energy density, and safety. Kerosene has matched all those requirements, but the growing need to reduce greenhouse gas (GHG) emissions makes the continued use of this fossil fuel less viable for aviation.

Various alternatives are available-drop-in replacement fuels from vegetable oils and Syn-Jet can be blended with kerosene and used completely interchangeably with conventional fuel [8]. They have generated significant interest from aviation stakeholders, but there are issues that need to be resolved. For instance, although vegetable oils are available in large quantities, their use as a fuel could lead to conflicts with food production. Syn-jet, having nearly identical properties to kerosene, would not solve environmental concerns due to its high carbon content. Significant investments in manufacturing are also required to produce drop-ins in sufficient quantities for the aviation sector. Additionally, the production of drop-in fuels can still contribute to net lifecycle $\mathrm{CO}_{2}$ and pollutant emissions. Cryogenic fuels such as LNG, liquefied biomethane, and liquid hydrogen $\left(\mathrm{LH}_{2}\right)$ are attractive alternatives due to their high specific energy density, but they are at a disadvantage compared to other fuels in terms of their volumetric energy density, meaning that they require greater storage volume, a critical aspect for aviation. Figure 1 summarizes the differences between potential alternative fuels for aviation with regard to energy density, including both specific energy density (SED) and volumetric energy density (VED) [9].

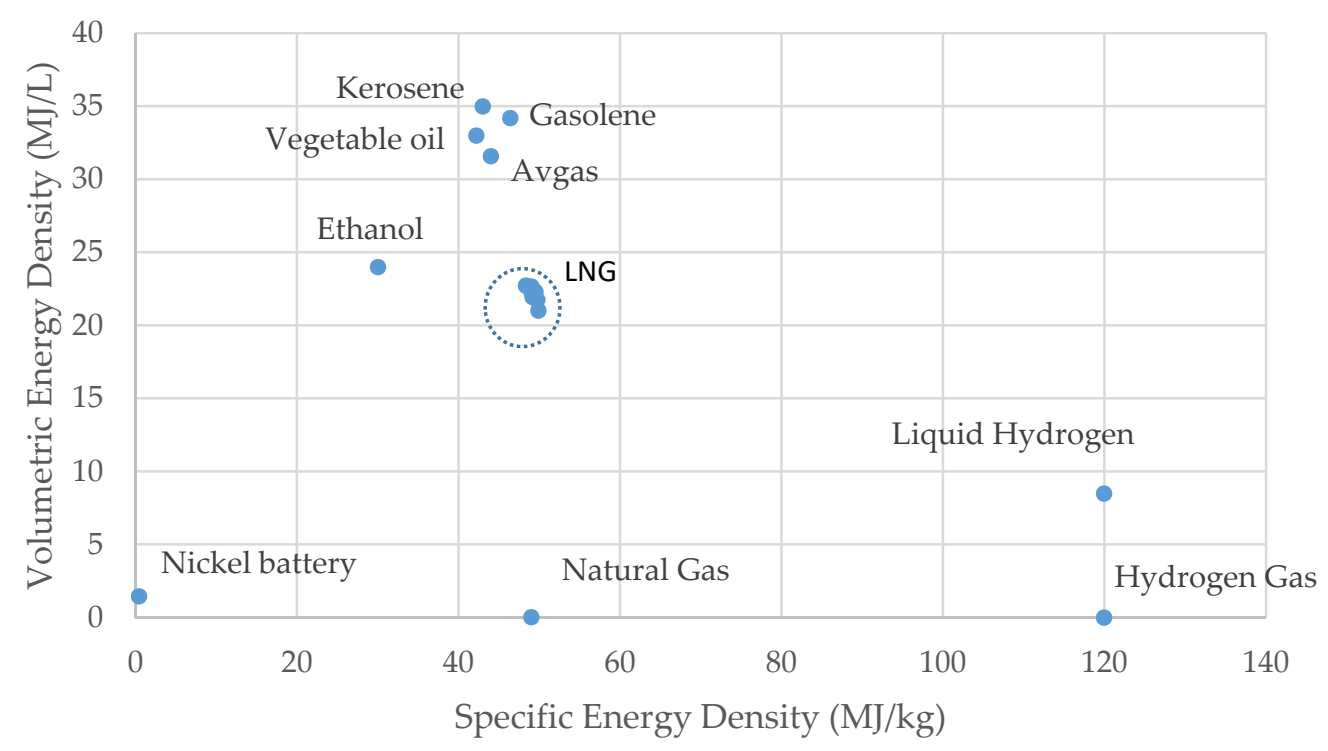

Figure 1. Fuel energy density comparison chart. 
Kerosene is at the top of the chart, which makes it an ideal candidate for aviation. Just below are other fuels with high carbon contents and which are naturally in liquid states. With a decrease in the carbon-to-hydrogen ratio, there is a reduction in $\mathrm{CO}_{2}$ emissions after combustion. This makes the fuel more attractive from an environmental point of view. However, this is accompanied by a decrease in the volumetric energy density, which implies that for a fixed specific energy density, more storage space is required in the fuel tanks to store the same amount of energy. Even in its cryogenically cooled liquid state, the volumetric energy density of natural gas is 35\% less than for kerosene, while the volumetric energy density of hydrogen is reduced by $75 \%$ compared to kerosene. Although $\mathrm{LH}_{2}$ has approximately $170 \%$ higher specific energy density compared to kerosene and has the potential for zero carbon emissions if produced cleanly, its implementation would require a complete redesign of the aircraft and propulsion systems. Furthermore, scaling-up green hydrogen production is still a significant challenge.

Natural gas, which is mostly methane, has been suggested as an alternative fuel for aviation, and liquefying it minimizes the fuel tank weight and volume. Several prior studies have been conducted to assess LNG use for subsonic aircrafts.

In 1980, the Beech Sundowner, a two-seater turboprop, was the first aircraft to operate on liquid methane [10]. Around the same time, Lockheed performed a thorough analysis on the prospects of LNG in civil aviation. They concluded that the modifications required to implement the use of a cryogenic fuel were too extensive to make sense economically, given the low price of kerosene at that time [8]. In 1988, a modified Tupolev TU-154, the TU-155, had its first flight, with one of its three engines operating on LNG. The aircraft performed several demonstration flights to international airports in Moscow, Bratislava, Nice, Berlin, and Hannover, which totaled more than 100 flight hours [10]; the project was discontinued after the fall of the Soviet Union.

NASA came to the conclusion that the use of methane had the potential to be competitive in all major areas, reducing the direct operating cost, gross weight, initial cost, and energy utilization if appropriate standards of handling and safety were maintained [11]. Following this, a similar study was performed by AIR-LNG, who instead inserted the tanks in LD6 containers within the cargo bay, whereby the only modification to the aircraft fuel system was the addition of LNG equipment. Through the partial or full replacement of kerosene, they estimated the possibility of implementing LNG for air transport within a timeframe of 3-6 years [12]. Although this configuration can be implemented with little redesign, which makes its implementation feasible in such a short timeframe, less space is available for the storage of LNG which reduces the range capability of LNG-flown aircraft. More recently, the start-up company Savion Aerospace proposed a business turboprop aircraft design cruising at Mach 0.55 and powered using LNG. Specifically, the founder, Jonathan Gibbs, claims that by using existing engines and retrofitting the combustor to burn natural gas, $75 \%$ of the development cost can be reduced, with the added benefit of a $15 \%$ reduction in maintenance costs due to the lower sulfur content [13].

However, the implementation of LNG in aviation has some underlying complexities that need to be addressed first. For instance, airports will need to accommodate large LNG storage tanks or liquefaction facilities in addition to pipelines to ensure safe and effective refueling. In addition, extra safety measures need to be taken due to the properties of this fuel. For instance, in case of a crash in water, water must not be allowed to enter the tanks due to the violent reaction of LNG with water.

Nevertheless, the world could significantly benefit both economically and environmentally from using LNG in aviation if those hurdles were addressed. Following the discovery and expansion of vast reserves of natural gas using shale fracking, the price of natural gas dropped significantly, and in 2020 reached its lowest level since 1995 [14]. In addition to it having a 16\% higher heating value and a higher hydrogen-to-carbon ratio molecule than Jet A, LNG presents itself as a competitive alternative aviation fuel. In this context, LNG could prove itself to be a clean alternative and act as a stepping stone towards the development of net-zero carbon emission alternatives, such as biomethane or hydrogen.

This paper aims to assess the performance benefits achieved in terms of $\mathrm{CO}_{2}$ emissions and energy-saving potential by replacing kerosene with LNG, in addition to discussing the challenges 
presented by the use of a cryogenic fuel for aircraft propulsion. In order to achieve this, an integrated design and simulation framework are developed and applied for the case of a single-aisle, short-range aircraft that is extensively used in civil aviation. The assessment is performed at the mission level, taking into consideration the effects of fuel synthesis on engine performance and accounting for the added weight and drag due to the necessary changes to the airframe. To the authors' knowledge, such a holistic assessment addressing the multitude of factors affecting aircraft and engine performance and discussing the implications of the required modifications had not previously been published within the research community.

\section{LNG Challenges}

LNG has the potential to act as a cleaner alternative to jet fuel. However, several technical challenges have to be addressed prior to considering it as a solution for aviation. To begin with, the varying composition of natural gas, depending on its source, affects both the lower heating value (LHV) and the density of the fuel, potentially affecting the aircraft performance. Additionally, both airframe and engine modifications are required before being able to use this cryogenic fuel. Another factor that needs to be taken into consideration is the environmental implications of using LNG in terms of $\mathrm{CO}_{2}$ emissions. For instance, the combustion of LNG compared to jet fuel leads to a reduction in $\mathrm{CO}_{2}$ emissions. However, methane, which is its major constituent, is a higher contributor to global warming. The escape or non-combustion of just $1 \%$ of the fuel would more than wipe out its global warming benefits in terms of $\mathrm{CO}_{2}$ emissions reductions. This section aims to give a brief description of the underlying implications and challenges that come with the use of LNG.

\subsection{LNG Compositions}

Natural gas is available in several countries and its composition varies significantly depending on the field. The differences in composition mean that the fuel properties vary, for example the higher heating values (HHV) can vary from 27.5 to $48.7 \mathrm{MJ} / \mathrm{m}^{3}$ between different European fields [15]. LNG synthesis and properties also vary depending on the source, albeit the heating value (HV) fluctuations are smaller due to $\mathrm{CO}_{2}$ and $\mathrm{N}_{2}$ removal to meet specifications for pipeline transport [16,17]. For this study, the lower heating values for different LNG sources are considered in order to assess the effect that this diversity may have. The LHV is calculated based on the composition reported in [18] utilizing the ISO method [19]. The values considered range from 48,339 to $49,877 \mathrm{~kJ} / \mathrm{kg}$, as seen in Figure 2. Additionally, the composition affects the density. As seen in Figure 3, for the case of LNG liquefied at $-160{ }^{\circ} \mathrm{C}$, the density values vary from 421.4 to $470.2 \mathrm{~kg} / \mathrm{m}^{3}$ for the cases examined herein; the density is calculated according to ISO 6578 [20]. These results indicate that for a specific aircraft and tank volume, the aircraft onboard energy will depend on the LNG composition available at the airport.

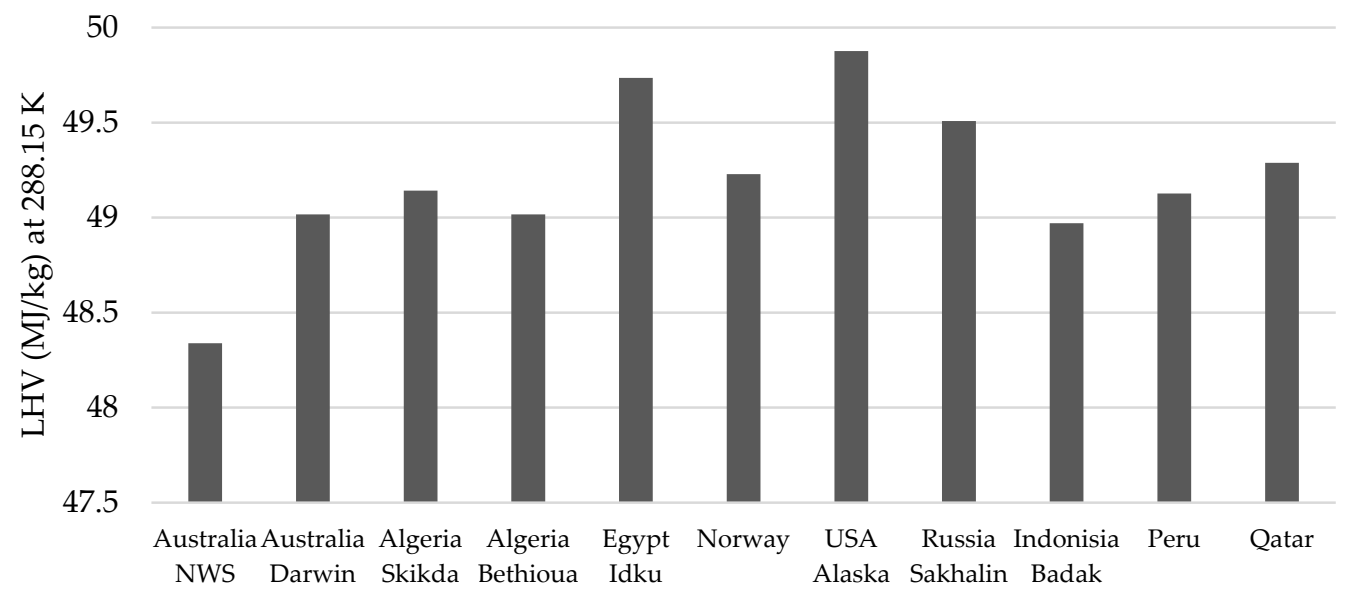

Figure 2. Variations in LHV per Region. 


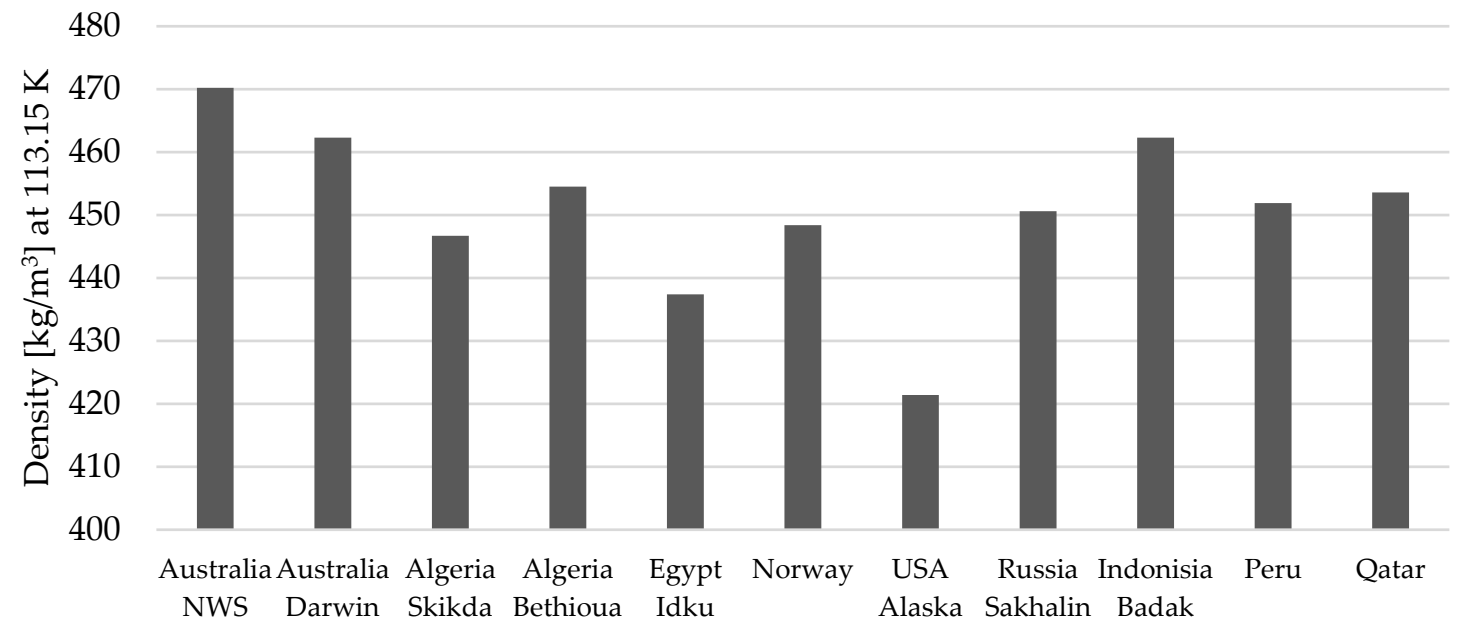

Figure 3. Variations in density per region at $113.15 \mathrm{~K}$.

Another parameter of interest is the $\mathrm{CO}_{2}$ potential of the LNG, which is depicted in Figure 4, expressed in the form of a $\mathrm{CO}_{2}$ emission index. However, it is apparent that the environmental footprint is not significantly affected by the source.

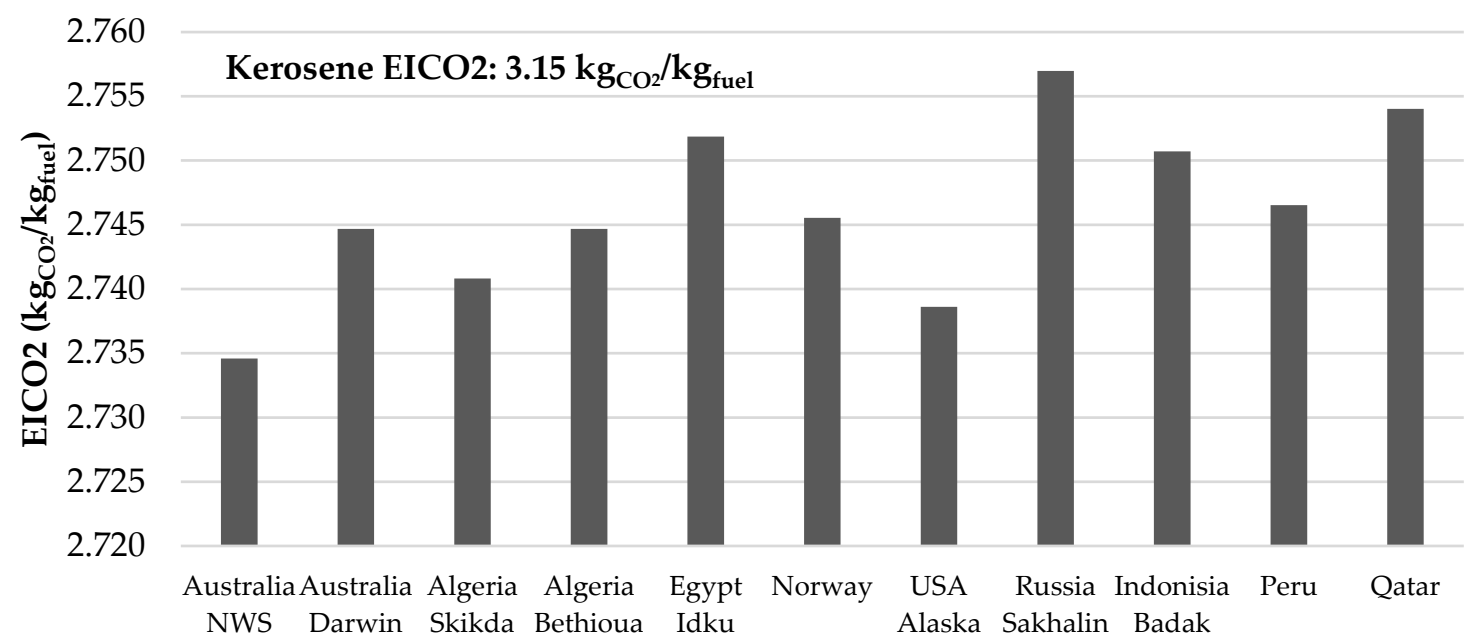

Figure 4. Variations of $\mathrm{CO}_{2}$ emission index per region.

From these data, three cases are selected in order to assess the effects of composition variation on the application of LNG for aviation. The selection is made with respect to the LHV and density. The highest LHV LNG from the data is the Alaskan source (type 1), the lowest LHV and highest density is the North West Shelf (NWS) source (type 3), while the Sakhalin source (type 2) is selected as a representative source.

\subsection{Airframe Chalenges}

Modifications are required on various fronts to enable the use of LNG. From an airframe perspective, the conventional tube-and-wing architecture requires extra storage space to accommodate the fuel. Given that cryogenic tanks will be required, their placement within the wings is less feasible. Some possible alternatives are shown in Figure 5. The conventional tube-and-wing configuration will increase in length if the tanks are placed at the front and at the back of the fuselage, and fuel must be drawn from both tanks together to prevent the center of gravity of the aircraft from moving beyond acceptable limits. Alternatively, the tanks could be placed at the top of the fuselage, which would lead to a larger frontal area. External tanks beneath the wings might also be used. Although this 
would provide wing bending moment relief, because of the larger surface area exposed to the external air flow, the boil-off rate would be higher compared to the other two configurations. Other airframe configurations could also provide greater storage capacity without impinging too much on the lift-drag ratio, which is inevitably reduced in the conventional tube-and-wing aircraft case. The double-bubble configuration is a promising candidate, which does not look too different from the tube-and-wing configuration. Alternatively, the blended wing body (BWB) configuration could provide more storage space in addition to a significant improvement in lift-to-drag ratio. However, a BWB design would probably require significantly more time to be implemented.

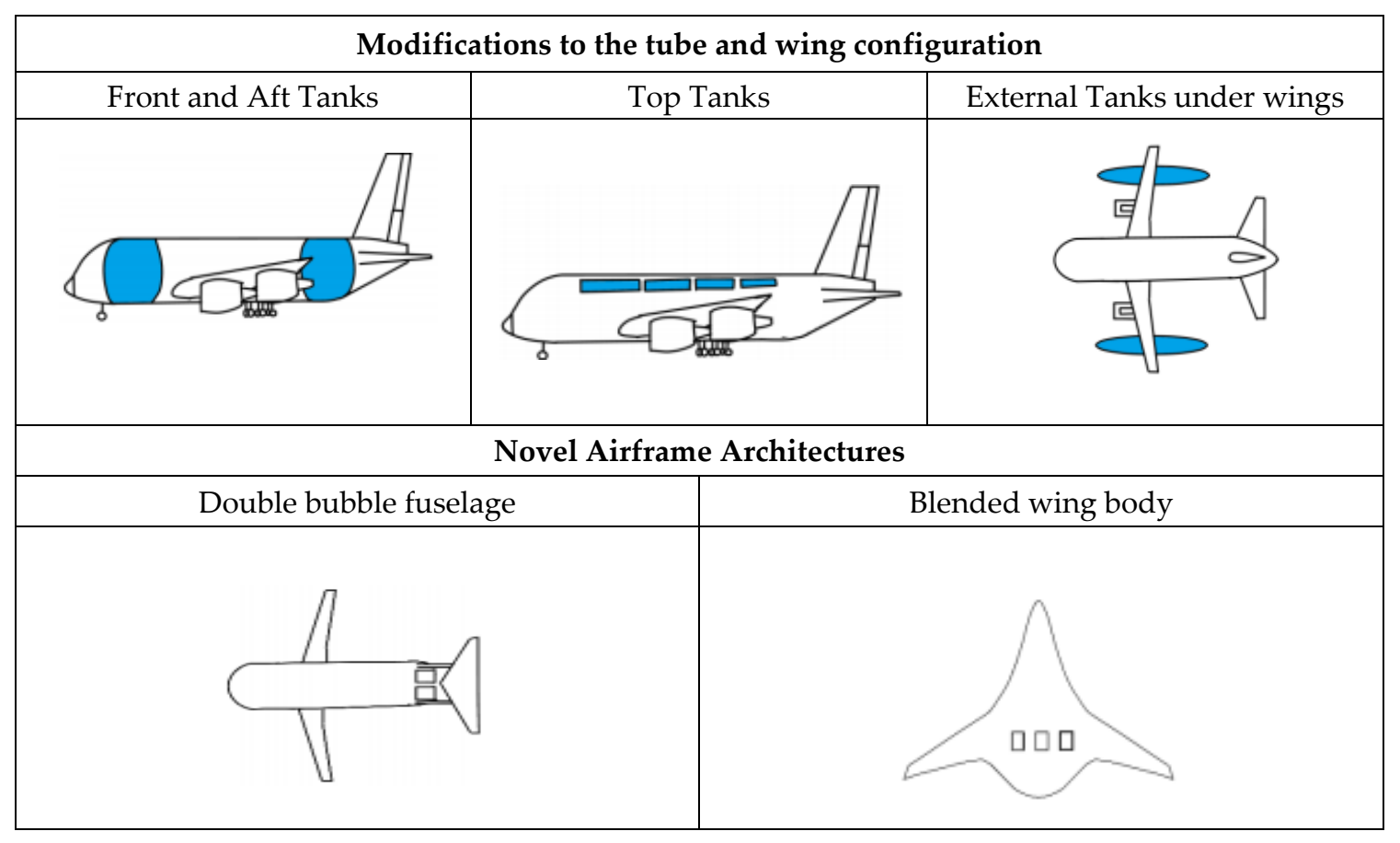

Figure 5. Modifications to the tube-and-wing configuration.

\subsection{Engine System Modifications}

In terms of engine modifications, changes are required to the combustor and the fuel system, including the fuel pumps and injectors. Due to the higher stoichiometric flame temperatures potentially obtained during the combustion of LNG, combustion chambers need to be redesigned to modify the rate at which air enters in order to provide rapid mixing to prevent pockets of very high temperature gas forming, which would favor the formation of NOx. Additionally, LNG needs to be in a gaseous state before entering the combustion chamber. The fuel injectors required to handle liquid fuel need to be completely redesigned.

The cooling potential of LNG could be utilized by using a heat exchanger to reduce the temperature of air bled from the compressor to cool the turbine blades, hence reducing the amount of air needed from the compressor to improve the thermal efficiency of the core. The fuel distribution pipes also need to accommodate LNG in both liquid and gaseous states. Boil-off gas from the tanks could be mixed with the gasified LNG after the heat exchanger and supplied to the engine.

\subsection{Global Warming Potential of LNG}

The GHG emission potential of using LNG is not always apparent. For instance, leakage of LNG at any point during its transport and distribution could have a higher negative impact on the environment due to its higher global warming potential (GWP) compared to $\mathrm{CO}_{2}$. Methane has a GWP of 28-36, while $\mathrm{CO}_{2}$ (which is used as the reference) has a GWP of 1. Although natural gas in the atmosphere has 
a shorter lifespan, which is reflected in the GWP index, it could lead to the generation of ozone, which is another GHG. Due to methane's higher hydrogen to carbon ratio, more water will be produced during the combustion process, which could lead to the formation of more contrails, which may contribute to global warming. However, the reduction in soot and sulfur-containing particulate emissions may help reduce the optical intensity of the contrails. Flight trajectories could be modified in the future to account for weather conditions in order to minimize the formation of contrails [21].

\section{Methodology}

To assess the performance of LNG-fueled aircraft, a design and simulation framework was developed, integrating Cranfield University's aircraft performance tool Orion [22] with a detailed LNG tank sizing module and an aircraft weight estimation module. The different modules require certain codependent inputs to size the aircraft. For a given propulsion system, a loop is required for the design mission, combining aircraft performance, tank sizing, and weight estimation. For example, for an initial estimation of the OWE of the aircraft, the onboard fuel is calculated and is used to estimate the weight of the tanks. The weight of the tanks is then fed back to the weight estimation, together with the calculated take-off weight (TOW) and landing weight (LW). The OWE is then recalculated and introduced back into the aircraft performance assessment. This loop ends when the OWE of the previous step matches that of the next. The loop is schematically presented in Figure 6.

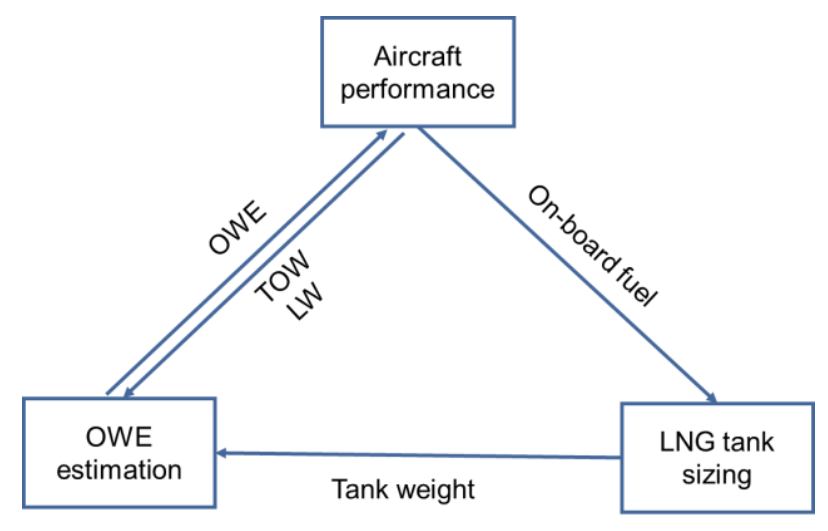

Figure 6. Design mission sizing loop.

\subsection{Aircraft and Engine Performance Modeling}

In-house tools were utilized to simulate the aircraft and engine performance. For the aircraft, Orion was used to predict the aerodynamic characteristics given the required inputs for an aircraft, combined with Turbomatch, the engine performance tool, in order to calculate the overall performance as an integrated aircraft-engine system. The point mass method was utilized, which equates the rate of work done by forces acting on the aircraft to the rate of increase in potential and kinetic energy (total energy model) $[23,24]$.

Turbomatch is an in-house 0-D performance simulation code, also featuring off-design (OD) and transient simulation [25]. A library of several pre-programmed modules corresponding to models of individual gas turbine components was used to set up the engine model. Due to its modular structure, a number of optimizers and simulators may use the capabilities of Turbomatch. It has been used extensively to perform aircraft-engine studies, emissions studies, and techno-economic and environmental risk analyses (TERA) [26].

\subsection{Aircraft Weight Estimation}

The weight estimation module is based on the method developed by NASA [27] as part of the flight optimization system (FLOPS). It includes different estimation modes according to aircraft type (i.e., civil aviation, fighter, or general aviation) for all the components contributing to the OWE, and is 
preferred instead of the methodologies of Raymer [28] and Roskam [29] due to the capability to also estimate the weight of conceptual BWB airframes. Wells [27] provided a detailed description of the equations and inputs required and Horvath [30] validated the tool and discussed some differences between the weight estimation methods.

The tool was also validated in this study using six tube-and-wing aircrafts with different sizes and range capabilities. The airframe data and geometry were derived from the corresponding aircraft characteristics for airport planning documents [31,32] and each engine weight was used directly as an input. The validation results are presented in Table 1 in terms of the predicted OWE and its component breakdown. In all cases, due to a lack of detailed information, only the estimated OWE could be compared against the manufacturer's quoted values. The tool presents only small prediction errors.

Table 1. Weight estimation tool validation.

\begin{tabular}{ccccccc}
\hline Aircraft & $\mathbf{7 3 7 - 2 0 0}$ & $\mathbf{7 3 7 - 8 0 0}$ & $\mathbf{7 6 7 - 2 0 0}$ & $\mathbf{7 7 7 - 2 0 0 L R}$ & $\mathbf{A 3 2 0 - 2 0 0}$ & A340-200 \\
\hline Structure total & 14.1 & 20.2 & 41.6 & 91.2 & 20.8 & 70.8 \\
Propulsion total & 3.6 & 6.0 & 11.3 & 22.4 & 6.1 & 13.8 \\
Systems and Equipment total & 8.6 & 12.0 & 16.7 & 25.0 & 11.9 & 24.4 \\
Operating items total & 1.5 & 2.5 & 4.9 & 7.1 & 3.1 & 7.2 \\
Predicted OWE & 27.9 & 40.7 & 74.6 & 145.7 & 41.9 & 116.2 \\
Actual OWE & 28.4 & 41.4 & 79.0 & 146.0 & 42.6 & 117.9 \\
\hline Prediction Error & $-1.90 \%$ & $-1.74 \%$ & $-5.54 \%$ & $-0.26 \%$ & $-1.62 \%$ & $-1.48 \%$ \\
\hline
\end{tabular}

\subsection{LNG Tank Sizing}

\subsubsection{Tank Shape}

Similarly to liquid hydrogen $\left(\mathrm{LH}_{2}\right)$, $\mathrm{LNG}$ needs to be stored in an isolated environment to avoid contact with air, therefore pressurized vessels are used for storage and transportation. Integrating such storage on aircrafts poses a big challenge. Currently, in civil aviation, kerosene is mostly stored inside the wings and occasionally in the fuselage, however the available internal space in the wings would lead to heavy cryogenic fuel tanks, which are unlikely to hold all the fuel required to match the range characteristics. Therefore, spherical tanks can be used, as demonstrated by the Boeing Phantom eye [33] or cylindrical tanks with hemispherical or ellipsoidal cap ends, as suggested in [34,35].

\subsubsection{Tank Walls}

The tank comprises walls and insulation. The walls have to withstand the pressure loads caused by the pressure difference between the fuel and the ambient air. A NASA study [36] on an LNG-fueled subsonic aircraft, and afterwards Brewer [37] and Winnefeld [38] suggested the use of Al 2219 due to its ease of manufacture, performance under cryogenic temperatures, and its ability to maintain the structural integrity of the tank. The wall thickness is determined by Equation (1) for the cylindrical part and by Equation (2) for the hemispherical cap ends [39] according to the internal tank diameter $\left(D_{0}\right)$, the maximum allowable pressure difference $(\Delta p)$, a pressure related factor of safety (FoS), the maximum allowable strength of the material $\left(\sigma_{a}\right)$, and the weld efficiency $\left(e_{w}\right)$. In this study, a $\Delta p$ value is considered that would not exceed $200 \mathrm{kPa}$ for short-range missions and the $\mathrm{SF}$ is set to 2.2, as discussed by Brewer [37]. The wall material properties and sizing parameters are shown in Table 2.

$$
\begin{aligned}
t_{w} & =\frac{D_{0} \times \Delta p \times F o S}{2 \sigma_{a} e_{w}-1.2 \times \Delta p \times F o S} \\
t_{w} & =\frac{D_{0} \times \Delta p \times F o S}{4 \sigma_{a} e_{w}-0.4 \times \Delta p \times F o S}
\end{aligned}
$$


Table 2. Al 2219 tank wall design properties.

\begin{tabular}{ccc}
\hline Parameter & Units & Value \\
\hline Maximum allowable strength, $\sigma_{a}$ & $\mathrm{MPa}$ & 172.4 \\
Density, $\rho$ & $\mathrm{kg} / \mathrm{m}^{3}$ & 2840 \\
Factor of Safety, FoS & - & 2.2 \\
Maximum allowable pressure difference, $\Delta p$ & $\mathrm{kPa}$ & 200 \\
Weld efficiency, $e_{w}$ & - & 0.8 \\
\hline
\end{tabular}

\subsubsection{Insulation}

The second component of the tank wall, the insulation, prevents excessive heat flux between the ambient air and the fuel. As heat is transferred through the tank walls, the fuel is heated and evaporates. The higher the insulation thickness, the lower the heat flux, and therefore the lower the total fuel evaporated; however, increased insulation thickness also leads to heavier tanks.

For $\mathrm{LH}_{2}$ flight weight tank applications, there are several types of insulation proposed, and the outstanding ones, as discussed by Kandelwa [40], are vacuum, multilayer, and rigid foam. Vacuum insulation offers the lowest thermal conductivity with close to zero boil-off rates, but with the disadvantage of having heavy outer walls to avoid buckling due to external pressure. Multilayer insulation has higher thermal conductivity than vacuum insulation but also is a heavy option. Rigid polymer foam insulation has higher thermal conductivity than the previous options but offers a good combination of low density, ease of implementation and manufacture, and low cost. Given that the LNG is stored at higher temperatures than $\mathrm{LH}_{2}$, and hence the levels of heat transfer are significantly lower, foam insulation is selected. A list of potential materials used by Colozza [41] is presented in Table 3.

Table 3. Polymer foam insulation materials and properties [41].

\begin{tabular}{ccc}
\hline Insulation Type & Density $\mathbf{( k g / \mathbf { m } ^ { 3 } )}$ & Thermal Conductivity (W/m K) \\
\hline Polymethacrylimide, Rigid, Closed-Cell & 35.3 & 0.0096 \\
Polyurethane, Rigid, Open-Cell & 32.1 & 0.0112 \\
Polyvinylchloride, Rigid, Closed-Cell & 49.8 & 0.0046 \\
Polyurethane +10\% Chopped Glass Fibres, & 64.2 & 0.0064 \\
Rigid, Closed-Cell & & \\
\hline
\end{tabular}

\subsubsection{Sizing and Heat Transfer Model}

The calculation of the tank dimensions is a straightforward process using cylindrical and spherical shell geometries. For a given insulation thickness, the dimensions are then defined according to any two of the following parameters:

1. Total fuel stored, which according to fuel density defines the internal volume, with an extra ullage of $7.2 \%$ considered, as discussed by Brewer [37];

2. The length of the cylinder;

3. The total tank length;

4. The external diameter.

The heat transfer model was adapted from previous $\mathrm{LH}_{2}$ tank sizing studies from Reynolds [42] and Colozza [41] and was adapted to the LNG application. The heat flux into the tank is estimated by balancing the heat transfer via convection $\left(Q_{c o n v}\right)$ and radiation $\left(Q_{r a d}\right)$ from the ambient air to the outer surface of the tank and the heat transfer via conduction $\left(Q_{\text {cond }}\right)$ through the insulation, as shown in Equation (3). A detailed description of the estimation of these terms is provided in [41] and is based on the tank cylinder dimensions (diameter and length), insulation thickness and properties, and the temperature of the ambient air and the LNG stored. It is also assumed that: 
- The heat transfer occurs naturally without any additional heat source;

- The tank has a constant volume (neglecting thermal expansion of the walls);

- The thermal resistance of the aluminium walls is discounted, as it is orders of magnitude lower than that of the insulation;

- The temperature of the inner surface of the tank is the same as that of the fuel.

The rate at which the fuel is evaporated, the boil-off rate ( $\left.m_{\text {boiloff }}\right)$, is calculated with Equation (4) according to the total heat transferred inside the tank and the latent heat from vaporization of the fuel $\left(h_{l g}\right)$. Integrating this at the mission level, different boil-off rates can be estimated for the varying ambient temperatures of every flight segment. Subsequently, multiplying this by the corresponding time and then summing the result will provide the total fuel evaporated throughout the mission, shown as Equation (5). If the evaporated fuel is unusable by the engines, several iterations will be required to re-size the tanks and compensate for the unusable fuel.

$$
\begin{gathered}
Q_{\text {cond }}=Q_{\text {conv }}+Q_{\text {rad }} \\
\dot{m}_{\text {boiloff }}=\frac{Q_{\text {cond }}}{h_{l g}} \\
M_{\text {evap }, \text { mission }}=\sum_{1}^{n_{\text {seg }}}\left[\dot{m}_{\text {boiloff }, i} \times t_{\text {segment }, i}\right]
\end{gathered}
$$

For the selection of the insulation material, a parametric study was carried out based on the properties presented in Table 3, with varying insulation thicknesses. The tank was sized for a defined mission profile, amount of fuel stored, and external diameters in all cases. The effect of increasing the insulation thickness on the total tank weight is presented in Figure 7. In the same graph, designs are also marked for each insulation material, such that all of them allow for the same amount of evaporated fuel throughout the mission. Evidently, rigid polyvinylchloride closed-cell foam provides the lightest design and occupies the least external space.

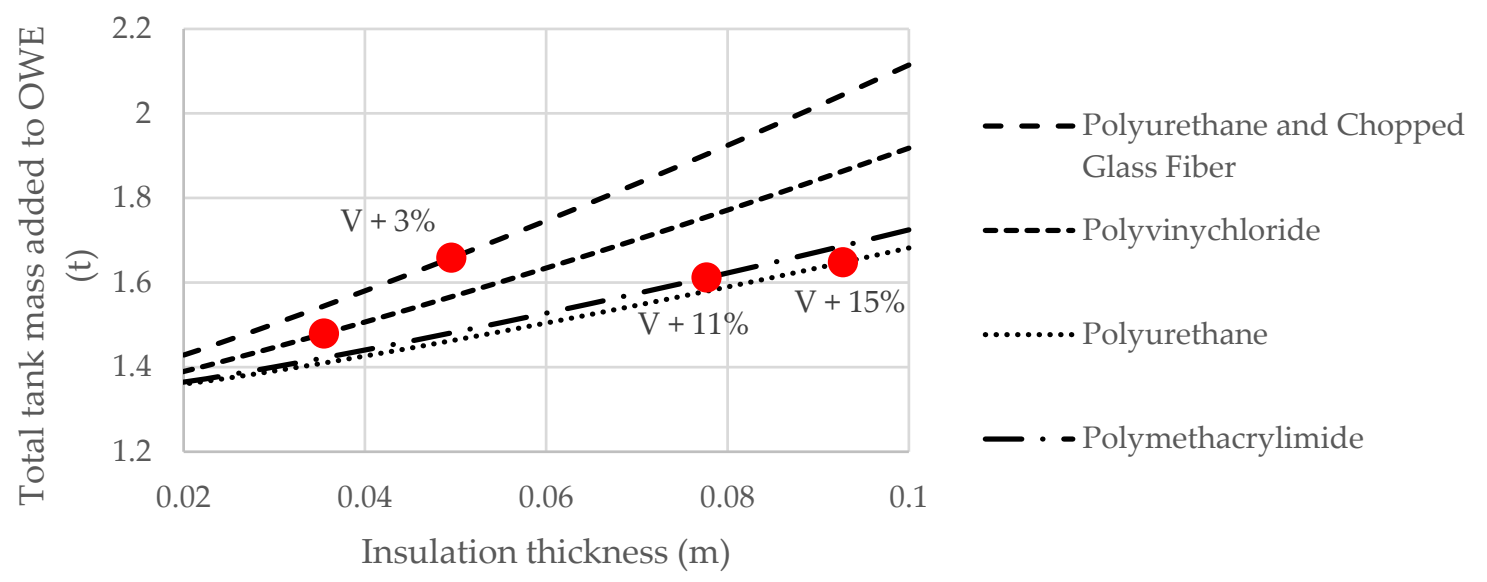

Figure 7. Total tank weight to insulation thickness.

\section{Case Study}

The aircraft model selected to demonstrate the LNG application was based on a Boeing 737-800, with a capacity of 185 economy passengers. The following section discusses the modeling of the baseline Jet A-1 model, the modifications considered for the LNG version, and the results and comparison of the different applications. 


\subsection{Turbomatch Engine Model}

The aircraft was equipped with two turbofan engines based on the CFM56-7B26, namely two-spool enginecapable of $117.4 \mathrm{kN}$ of thrust at sea level static (SLS) with $+30{ }^{\circ} \mathrm{C}$ ambient temperature [43]. A two-spool engine model was created in Turbomatch by matching available performance characteristics from [43] and assuming parameters such as component efficiencies, cooling bleeds, duct pressure losses, and power-off takes. In Table 4, the performance of the model is presented as simulated for three characteristic points-SLS, mid-cruise, and top of climb. Multipoint matching was used to input the underlined values in Table 4, while the remaining values are the results.

Table 4. CFM56-7B26 Turbomatch model.

\begin{tabular}{|c|c|c|c|c|}
\hline Parameters & Units & SLS & Cruise & Top of Climb \\
\hline Altitude & $\mathrm{ft}$ & $\underline{0}$ & 35,000 & 35,000 \\
\hline Mach Number & - & $\overline{0}$ & $\overline{0.8}$ & 0.8 \\
\hline dTisa & K & $\overline{15}$ & $\overline{0}$ & $\overline{0}$ \\
\hline Net Thrust & $\mathrm{kN}$ & 117.4 & $2 \overline{4.4}$ & $2 \overline{6} .5$ \\
\hline Bypass Ration & - & $\underline{5.1}$ & $\overline{5.2}$ & $\overline{5.1}$ \\
\hline Overall Pressure Ratio & - & $\overline{27.9}$ & 29.9 & 31.6 \\
\hline Inlet Air Mass Flow Rate & $\mathrm{kg} / \mathrm{s}$ & 355 & 150 & 153 \\
\hline Specific Fuel Consumption & $\mathrm{g} / \mathrm{kN}$ & $\overline{10.54}$ & $\underline{17.76}$ & 18.02 \\
\hline
\end{tabular}

\subsection{Jet A-1 Model}

The baseline aircraft model was then created by utilizing the engine model and the geometry of the aircraft found in [44]. Characteristic weights such as the maximum take-off weight (MTOW), operating weight empty (OWE), maximum payload, and fuel were also included. The flight profile used throughout the mission analyses that will follow is presented in Table 5, partially based on information from $[44,45]$.

Table 5. Flight profile.

\begin{tabular}{cc}
\hline Flight Profile Parameters & Inputs \\
\hline Calibrated Airspeed (CAS) Initial climb up to 10,000 ft & 250 \\
Calibrated Airspeed (CAS) Climb after 10,000 ft & 310 \\
Calibrated Airspeed (CAS) Descent & 300 \\
Contingency & $5 \%$ of theTrip Fuel \\
Diversion & $130 \mathrm{nmi}$ at $25,000 \mathrm{ft}$ \\
Hold & $30 \mathrm{~min} 1500 \mathrm{ft}$ \\
\hline
\end{tabular}

Based on the aforementioned inputs, the baseline model was compared to the actual performance of the aircraft, as quoted in [44], for three key missions-the maximum payload, maximum fuel, and ferry range. Standard day conditions with zero wind and normal power extraction from the engines were considered. It was assumed that for the maximum payload and fuel missions, the aircraft would cruise at $35,000 \mathrm{ft}$ (design cruising altitude) and at 0.78 and 0.76 Mach respectively; while for the ferry range mission the aircraft would cruise at $37,000 \mathrm{ft}$ and $0.75 \mathrm{Mach}$. The resulting payload-to-range diagram against the reference Boeing data is depicted in Figure 8. The results indicate that the engine aircraft performance is predicted with adequate accuracy for assessing system performance changes due to drag, weight, and fuel properties. 


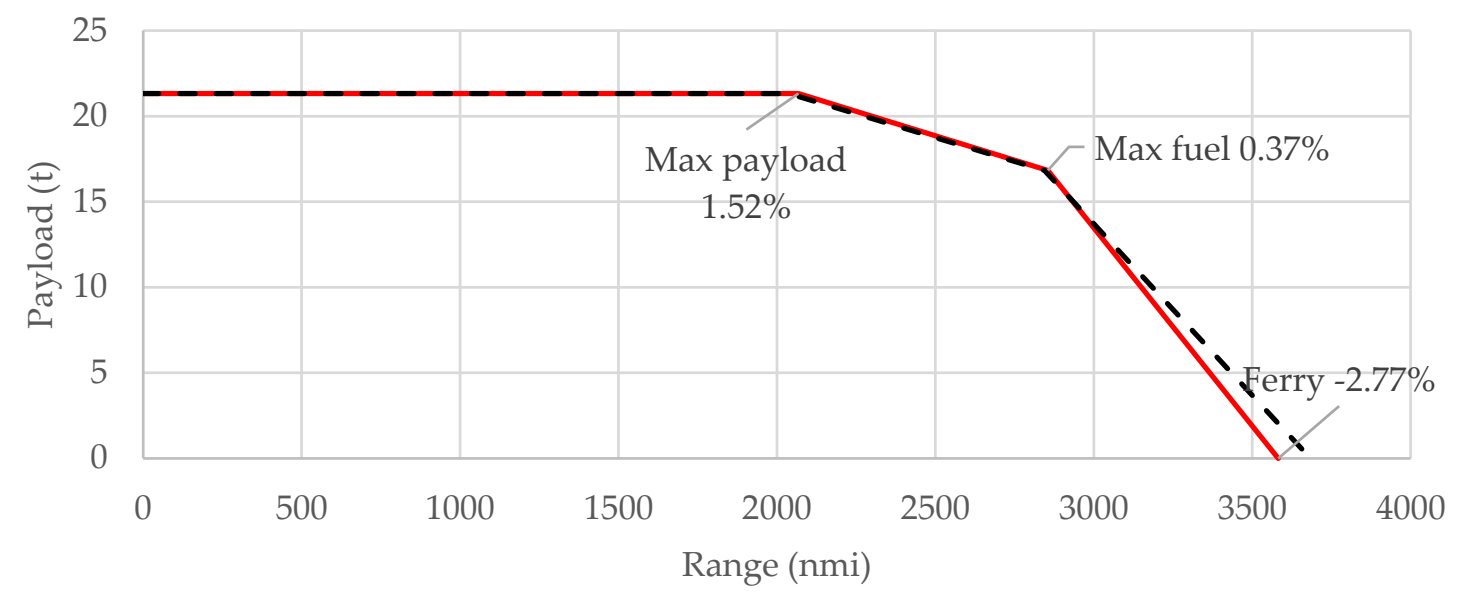

Figure 8. Payload-to-range performance for the baseline aircraft.

\subsection{LNG Model}

Converting the baseline aircraft to use LNG is not a straightforward process. Due to the size and shape of the tanks that need to be integrated, modifications are required. A solution would be to mount them inside the fuselage and reduce the passenger capacity; however, the resulting aircraft would not be comparable to the baseline. Therefore, it was considered that the two models would have a common mission, which would set the requirements for designing the LNG version. For this, the maximum fuel mission was selected, since the fuel tanks need to be sized for the maximum capacity. In the design mission, the LNG aircraft is capable of carrying a payload of 16.8 tons at a range of 2855 $\mathrm{nmi}$, with the same flight profile as the baseline model using the type 1 (Alaskan) LNG composition. As discussed, the performance of the aircraft will also be examined for the type 2 (Australian NSW) and type 3 (Sakhalin) compositions. The properties of the selected fuels used for sizing and analysis are presented in Table 6 and were calculated based on $150 \mathrm{kPa}$ initial storage pressure. Ideally, the lower the pressure, the higher the density; however, considering the potential difficulties related to refueling the tanks at close to ambient pressure, a slightly higher value was chosen. Of the three fuels, type 1, the design choice, has the highest LHV, and therefore would require less LNG mass than the other two. However, for the same volume, type 3 stores greater energy and could potentially allow for greater range capabilities. Finally, the $\mathrm{CO}_{2}$ emission index $\left(\mathrm{EICO}_{2}\right)$ greatly depends on the composition of the fuel.

Table 6. LNG fuels considered.

\begin{tabular}{ccccc}
\hline Properties & Units & Type 1 & Type 2 & Type 3 \\
\hline Pressure & $\mathrm{kPa}$ & & 150 & \\
Temperature $(\mathrm{K})$ & $\mathrm{K}$ & 116.3 & 116.9 & 109.8 \\
Liquid density $\left(\mathrm{kg} / \mathrm{m}^{3}\right)$ & $\mathrm{kg} / \mathrm{m}^{3}$ & 416.0 & 427.9 & 449.6 \\
LHV & $\mathrm{MJ} / \mathrm{kg}$ & 49.9 & 49.5 & 48.3 \\
Volumetric Energy density & $\mathrm{MJ} / \mathrm{m}^{3}$ & 20,751 & 21,185 & 21,733 \\
$\mathrm{EICO}_{2}$ & $\mathrm{kgCO}^{3} / \mathrm{kg}_{\text {fuel }}$ & 2.74 & 2.76 & 2.73 \\
\hline
\end{tabular}

Tank Position, Weight, and Aircraft Modifications

For tube-and-wing aircraft, the cryogenic tanks can be positioned in several locations. In a long-range application study, Brewer [38] suggested placing them forward and aft of the passenger cabin to maintain stability. In this case, however, these positions would require significant elongation of the fuselage, which would in turn require a longer undercarriage to avoid issues with the rotation angle of the aircraft. The Cryoplane [46] and ENABLEH2 (ENABLing cryogEnic Hydrogen-based CO2-free air transport) [47] studies suggested that placing the tanks on top of the fuselage would avoid such problems and lead to a more efficient design; therefore, such an arrangement was adopted for 
this application as well. The tanks were covered by fairing to protect them from external damage, reduce drag, and prevent higher heat transfer by forced convection from the free-stream air.

Considering the available space above the passenger cabin, several restrictions and assumptions were set. The fairing was assumed to have a thickness of $5 \mathrm{~cm}$, half of that of the main fuselage, because it did not contain a pressurized compartment. An additional spacing of $5 \mathrm{~cm}$ was considered between the inner fairing surface and the outer surface of the tanks. The weight per unit of wetted surface area was $10 \mathrm{~kg} / \mathrm{m}^{2}$, also half of that of the fuselage skin, as calculated by the weight estimation module. The center of gravity (CoG) position was assumed to be approximately $90 \%$ of the distance from the front to the rear undercarriage. The frontal area of the fairing matched the slope of the cockpit, and by mirroring the area around the CoG for balancing, a total internal length of $24.2 \mathrm{~m}$ was available. In order to avoid catastrophic damage if a rotor disc burst should occur, a spacing between area the tanks was considered. According to [48], the space situated $15^{\circ}$ from the fan face and $5^{\circ}$ from the turbine exit was left empty. The remaining available length was divided into two; the front was $7.3 \mathrm{~m}$ and the rear was $13.05 \mathrm{~m}$. These considerations are shown schematically in Figure 9.

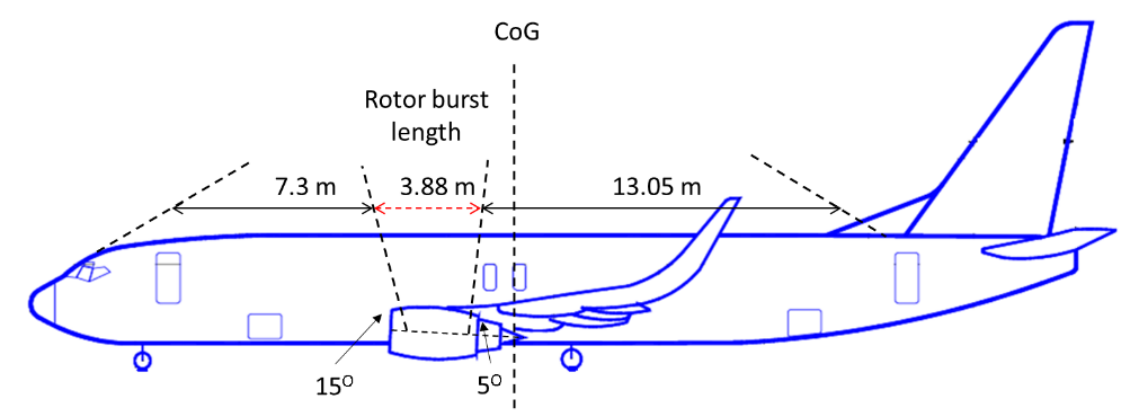

Figure 9. Schematic representation of the 737-800 type adopted from [44].

Multiple tanks can be accommodated in the available space, however only two were selected, since they would add the least surface area to the fairing, overall were a lighter option, and since they offered a lower surface-to-volume ratio in order to minimize heat transfer. Both tanks were considered to have the same external diameter, and in order to minimize this the front tank took up all of the available length. The selected external diameter allowed for a fuel split between the tanks that balanced the moment around the CoG developed by the added masses (tank and fuel). The insulation thickness of each tank was chosen to provide similar evaporation rates. Finally, the tank mountings were assumed to be $20 \%$ of the weight of tank.

\subsection{Results and Comparison}

The LNG aircraft was sized by utilizing the simulation framework, which combines all of the above-mentioned modules. Using the same propulsion system but with the type 1 LNG properties, the baseline aircraft was used as a starting point and was converted to the LNG application once the sizing loop converged (i.e., when the codependent inputs of all the individual modules were matched). In the following sections, the tank sizing results, the aircraft characteristic weights, and the payload-to-range characteristics for the three types of fuels are presented for the sized aircraft.

\subsubsection{Cryogenic Storage Properties}

To begin with, the sized tanks are presented in Table 7 . Based on the above considerations, both tanks had a diameter of $2 \mathrm{~m}$, the rear tank had an overall length of $12.2 \mathrm{~m}$ (within the set limits), and the fuel split between the front and the aft tank was 36-64\%, respectively. The thickness selected allows for a mission-evaporated fuel to total fuel stored ratio of approximately $0.3 \%$ for both tanks. The total added fuel storage weight for the aircraft is 3.9 tons and the added fairing increases the fuselage wetted area by $22.8 \%$. 
Table 7. Sized LNG aircraft tanks.

\begin{tabular}{ccccc}
\hline Tank Characteristics & Units & Fore Tank & Aft Tank \\
\hline External diameter & $(\mathrm{m})$ & & 2.0 & \\
Overall length & $(\mathrm{m})$ & 7.30 & & 12.18 \\
Insulation thickness & $(\mathrm{m})$ & 0.055 & & 0.05 \\
Design mission evaporated fuel & $(\mathrm{kg})$ & 19.7 & & 36.3 \\
Useful fuel mass & $(\mathrm{kg})$ & 7118 & & 12,536 \\
Total tank mass & $(\mathrm{kg})$ & 450 & & 929 \\
Fairing weight & $(\mathrm{kg})$ & & 2216 & \\
Total added weight & $(\mathrm{kg})$ & & 3928 & \\
\hline
\end{tabular}

\subsubsection{Weight Characteristics and Payload-Range Performance}

The weight characteristics are presented in Table 8 for the baseline model and the LNG variant. The sized aircraft is heavier than the baseline due to the addition of the fuel storage system, and in combination with increased wetted area, requires more energy. However, due to the higher LHV of the LNG compared to Jet A-1, less mass of fuel is required for the same mission. Overall, the combined effect leads to a slightly heavier maximum take-off weight (MTOW) and maximum landing weight (MLW). Figure 10 presents the payload-to-range diagram for the baseline aircraft and the LNG variant with the design choice LNG. Since the maximum fuel mission is the same, only the maximum payload and ferry range missions differ, where the sized aircraft shows a slight decrease in range in comparison to the baseline. Figure 10 also includes the performance of the LNG aircraft for the other two examined fuels. For the maximum payload mission, the fuel that can be carried is restricted by the MTOW and the payload, therefore the fuels with less LHV have up to $-5.7 \%$ lower range compared to the baseline. For the maximum fuel mission, the fuel that can be carried is dictated by the volume of the sized tanks, and due to the alternative fuel densities more fuel mass (and energy) can be stored, as shown in Table 8 . This leads to increased range but with a reduced payload, since the latter is restricted by the MTOW. The same applies for the ferry mission, where the alternative options provide longer range capabilities of up to $5 \%$ compared to the baseline.
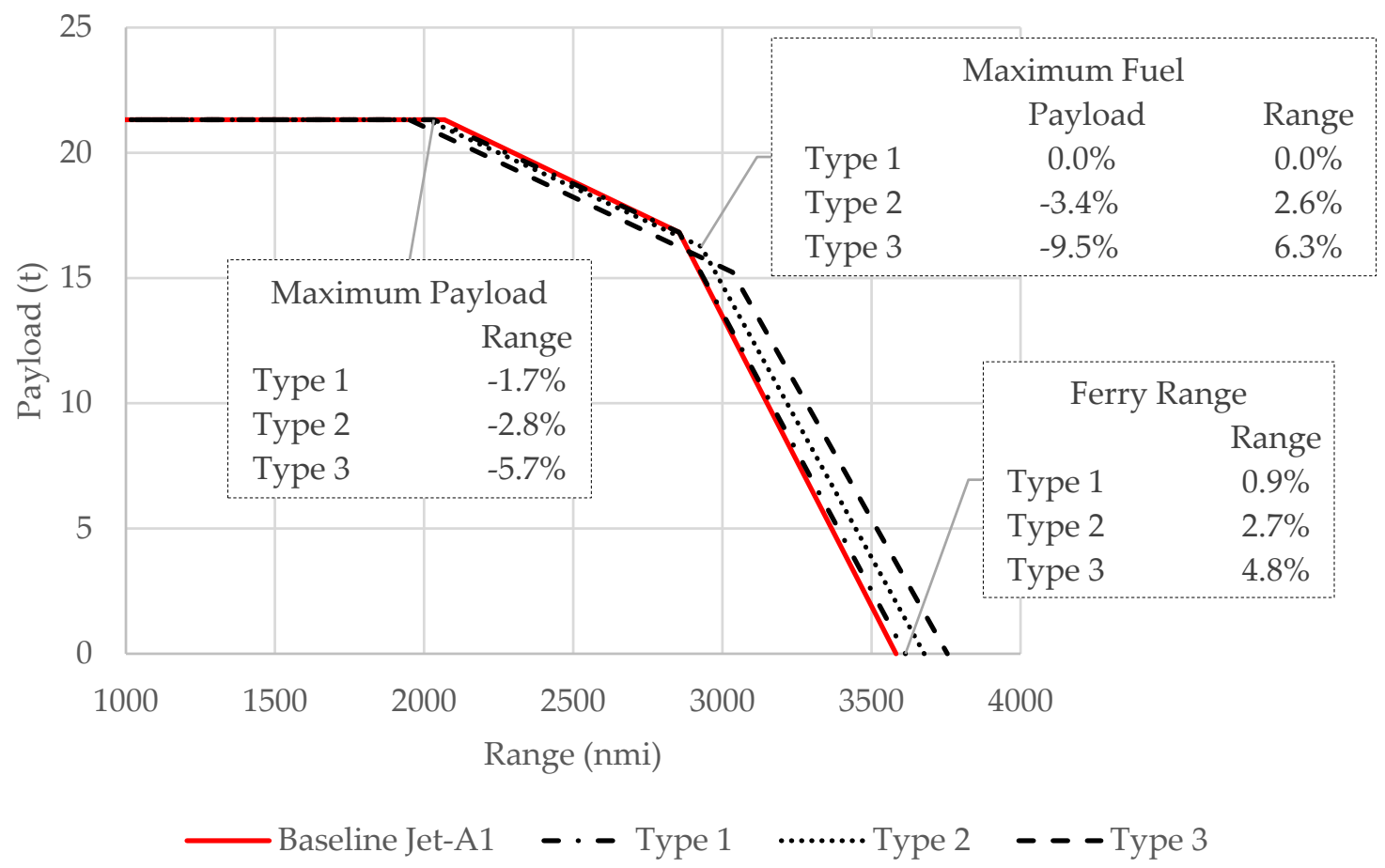

Figure 10. Payload-to-range diagram for the baseline model and the LNG variant with three fuel options. 
Table 8. Sized aircraft weight breakdown.

\begin{tabular}{clcccc}
\hline Characteristic Weights & Units & Jet-A1 Baseline & Type 1 & Type 2 & Type 3 \\
\hline MTOW & $(\mathrm{kg})$ & 79,016 & & 81,544 & \\
OWE & $(\mathrm{kg})$ & 41,413 & & 45,070 & \\
MLW & $(\mathrm{kg})$ & 65,217 & & 68,708 & \\
Maximum Fuel Capacity & $(\mathrm{kg})$ & 20,894 & 19,654 & 20,214 & 21,239 \\
Maximum Payload & $(\mathrm{kg})$ & & 21,319 & & \\
\hline
\end{tabular}

\subsubsection{Typical Mission Performance and Comparison}

For this assessment, the LNG aircraft with the three examined fuels carries a typical payload of 18.12 tons ( $85 \%$ of the maximum) for a range that varies from 250 to $2250 \mathrm{nmi}$, which is compared against the baseline. The flight profile for all the missions is the one proposed in Table 5, with a cruising speed of 0.78 Mach at $35,000 \mathrm{ft}$.

The results are presented in terms of the energy, fuel, and $\mathrm{CO}_{2}$ emissions per passenger nmi in Figures 11a, 12a and 13a, respectively and in Figures $11 \mathrm{~b}, 12 \mathrm{~b}$ and $13 \mathrm{~b}$, the corresponding differences of the LNG performance against the baseline are shown. Figure 11a shows that the LNG aircraft requires more energy due to the increased OWE and surface area than the baseline, while Figure 11b shows that less energy is consumed when the aircraft is using a LNG composition with higher LHVs (lighter aircraft). From Figure 12a, it can be observed that due to the fuel properties, less fuel mass is consumed by the LNG variant compared to the Jet-A1 baseline. Finally, in Figure 13 a the $\mathrm{CO}_{2}$ emissions are quantified, which do not present the same trend as the fuel burn, which is attributed to the differences in the $\mathrm{EICO}_{2}$. In Figure 13b, it is evident that by replacing LNG with Jet A-1, a reduction of at least $15 \%$ in $\mathrm{CO}_{2}$ emissions can be achieved for the particular application, and by using LNG with a higher methane composition the reduction can be maximized to $17-18 \%$. Finally, based on the fuel costs considered by Withers [49], the average fuel cost difference compared with Jet A-1 is presented in Figure 14. For this application, switching to LNG would potentially save about $16 \%$ on the cost of fuel.

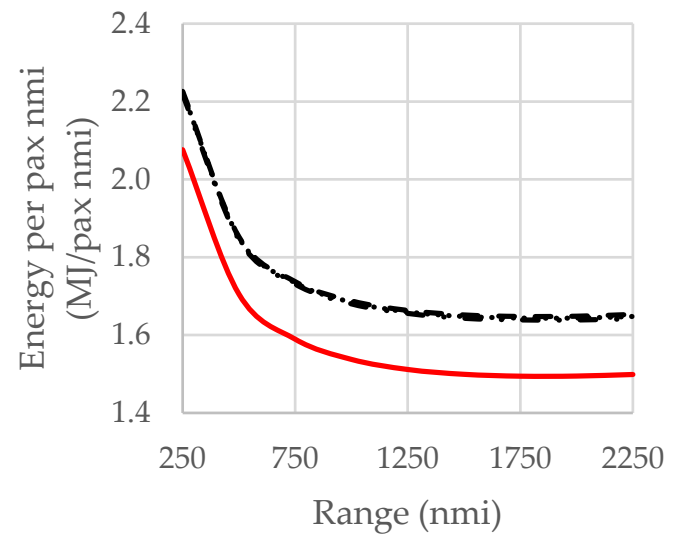

(a)

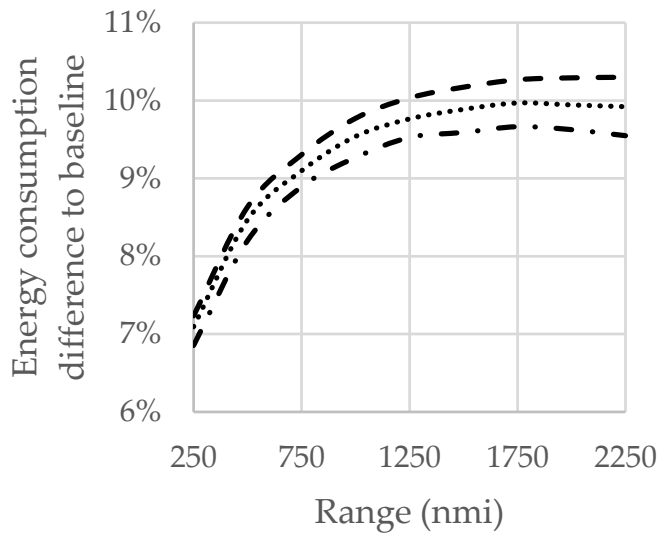

(b)

$$
\text { — Baseline Jet-A1 _ - - Type } 1 \quad \cdots \cdots \cdot . \cdot \text { Type } 2 \quad \text { - - - Type } 3
$$

Figure 11. (a) Energy per pax nmi against range and (b) corresponding difference from the baseline. 


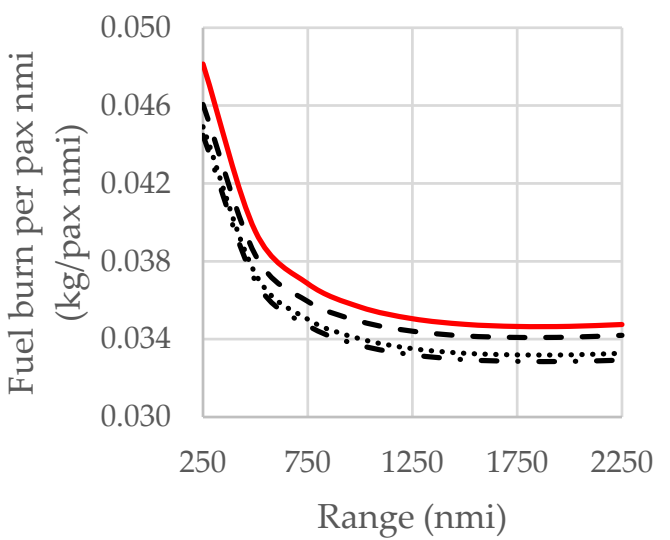

(a)

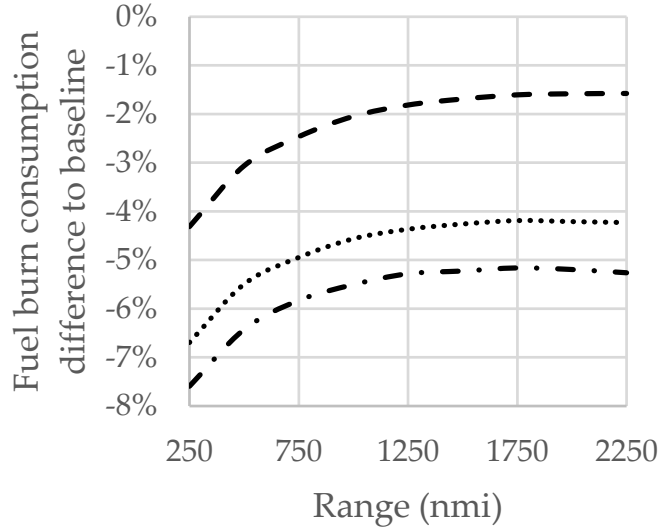

(b)

— Baseline Jet-A1 $\quad$-. - Type $1 \quad \cdots \cdots \cdot$.... Type $2 \quad$ - - - Type 3

Figure 12. (a) Fuel burn per pax nmi against range and (b) the corresponding difference from the baseline.

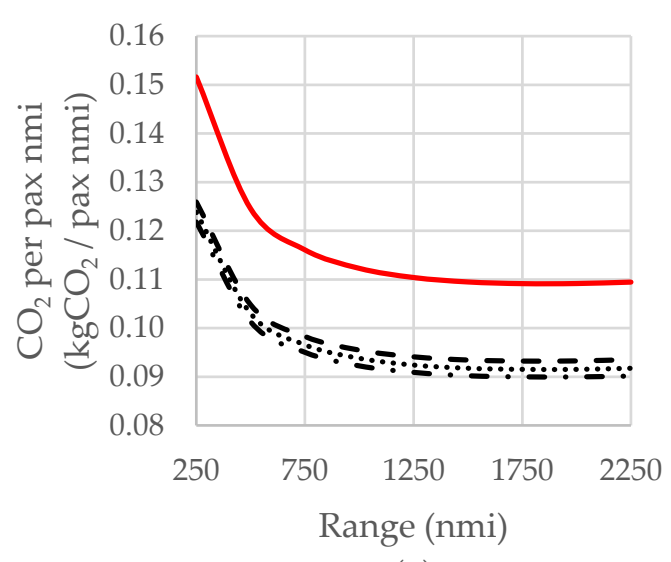

(a)

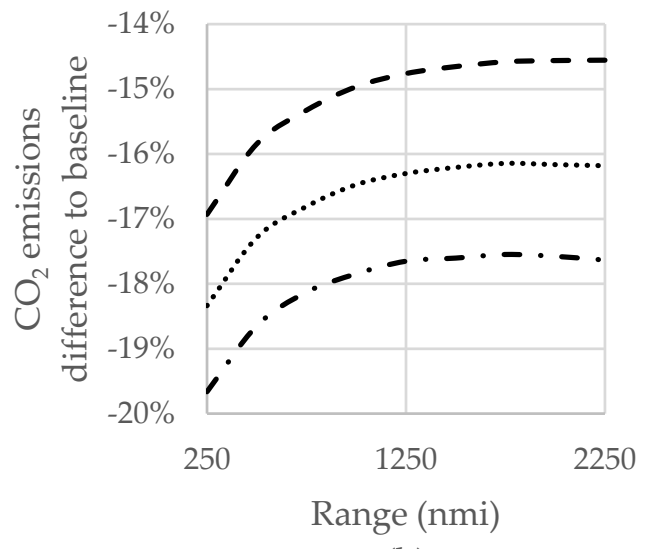

(b)

— Baseline Jet-A1 _ - - Type $1 \quad$ ……. Type $2 \quad$ - - - Type 3

Figure 13. (a) $\mathrm{kg}$ of $\mathrm{CO}_{2}$ emissions per pax nmi against range and (b) the corresponding difference from the baseline.

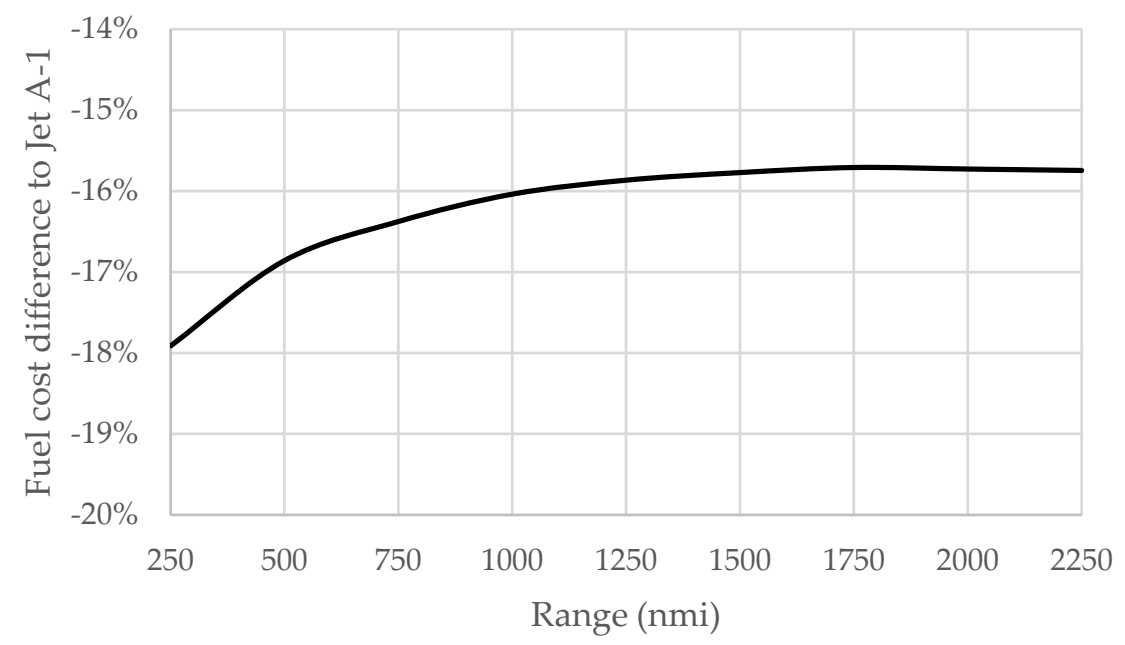

Figure 14. Average fuel cost difference to baseline Jet A-1. 


\section{Conclusions}

The potential benefits of introducing LNG in civil aviation were quantified by utilizing a simulation framework integrating aircraft engine performance models, a tank sizing module, and an aircraft weight estimation module. A case study based on the popular Boeing 737-800 aircraft was performed and the changes on the airframe weight and volume due to conversion to LNG were considered. The "above-the-passenger-cabin" tank configuration was selected, utilizing two cylindrical tanks with a frontal diameter of $2 \mathrm{~m}$, leading to an increased fuselage wetted area and higher drag. The front tank has a length of $7.3 \mathrm{~m}$ and the rear tank has a length of $12.2 \mathrm{~m}$, designed considering both safety issues and minimum impact on the aircraft's center of gravity. The added weight of the fuel storage system is 4 tons, resulting in an increase in the aircraft maximum take-off weight of $4 \%$ ( 2.5 tons). The aircraft performance was assessed against the baseline case (Jet A-1) for three different LNG sources in terms of the payload range performance, mission energy and fuel consumption, $\mathrm{CO}_{2}$ emissions, and fuel cost. The LNG-converted aircraft had a slightly reduced range for the case of maximum payload. The decrease in range varied from $1.7 \%$ to $5.7 \%$ for the different LNG sources. For the ferry mission, LNG with increased energy density provided a benefit in terms of range of $0.9-4.8 \%$ for the different sources. For the maximum payload, the added weight resulted in a decrease of range when LNG was considered, while for the ferry mission it was the fuel specific energy that provided the benefit, since there was no limitation on fuel mass due to payload. These results indicate that when assessing LNG for aviation, it is important to consider the source and synthesis, since these factors affects both LHV and density, and hence the mission-available energy. These are also operational parameters that have to be assessed if LNG is used in aviation, since aircraft performance will change depending on the take-off airport.

It is apparent that the increases of aircraft weight and frontal area for the LNG cases will result in higher energy consumption per passenger. The results indicate that the increase in energy will be in the range of $10 \%$ for a typical flight (1000-2000 nmi). Of course considering the difference between the LHV of kerosene and LNG, this is translated to a fuel reduction of $4 \%(1.6-5.0 \%$, depending on the source) for typical flights, and up to $6.7 \%(4.3-7.6 \%)$ reduction for the shortest flights that this aircraft operates (in the range of $250 \mathrm{nmi}$ ). This fuel reduction in conjunction with the lower $\mathrm{CO}_{2}$ index of LNG compared to kerosene offers a substantial $\mathrm{CO}_{2}$ emissions reduction in the range of $16 \%$ for typical missions and up to $18 \%$ for very short missions. The lower cost of LNG compared to kerosene offers a significant fuel cost per passenger reduction of approximately $16 \%$. In this context, it is apparent that LNG has significant environmental and economic benefits compared to kerosene, even when accounting for weight and drag penalties. It is also important to consider that gas turbine engines operate without the need for a major redesign or retrofitting with NG, while if we consider future propulsion configurations (e.g., hybrid-electric, supersonic), LNG thermal management capabilities may act as technology enablers. Of course, the adoption of LNG in aviation will have to address the current lack of infrastructure and the need for a new logistic approach considering aspects such as the source and synthesis, fuel delivery, and fuel stability. The prospects for LNG utilization in other transport industries (e.g., marine) may offer experience that can support its application for aviation.

Author Contributions: Conceptualization, P.R., I.R., S.K., A.R.; data and software contributions, P.R., D.N., A.R., T.N., S.K., I.R.; analysis, P.R., I.R., D.N., S.K., T.N.; writing-original draft preparation, P.R., S.K., I.R., T.N.; writing-review and editing, P.R., S.K., I.R., A.R. All authors have read and agreed to the published version of the manuscript.

Funding: This research received no external funding.

Conflicts of Interest: The authors declare no conflict of interest. 


\section{References}

1. World Economic Forum. Available online: https://www.weforum.org/agenda/2020/08/earth-iceglobal-warming-uk-scientists/\#: \{\}:text=Global\%20warming\%3A\%20This\%20is\%20how (accessed on 21 September 2020).

2. ATAG. Available online: https://www.atag.org/facts-figures.html\#: \{\}:text=The\%20global\%20aviation $\%$ 20industry\%20produces (accessed on 21 September 2020).

3. OliverWyman. Available online: https:/www.oliverwyman.com/our-expertise/insights/2019/jan/global-fleetmro-market-forecast-commentary-2019-2029.html (accessed on 21 September 2020).

4. EU Sustainable Energy Week. Available online: https://eusew.eu/sites/default/files/programme-additionaldocs/EUSEW2017-BF_FP.pdf (accessed on 21 September 2020).

5. European Union Website. Available online: https:/ec.europa.eu/transport/sites/transport/files/modes/air/ doc/fuel_report_final.pdf (accessed on 14 October 2020).

6. UK Defence Journal. Available online: https://ukdefencejournal.org.uk/rolls-royce-opens-new-facility-inbristol-to-develop-better-jet-engines/ (accessed on 14 October 2020).

7. Yen, J. Optimize the flight path for airlines using real-time information. In Proceedings of the 2015 IEEE International Conference on Automation Science and Engineering (CASE), Gothenburg, Sweden, 24-28 August 2015; p. 1649.

8. Alexiou, A.; Tsalavoutas, A.; Pons, B.; Aretakis, N.; Roumeliotis, I.; Mathioudakis, K. Assessing Alternative Fuels for Helicopter Operation. ASME J. Eng. Gas Turbines Power 2012, 134, 111401. [CrossRef]

9. Rao, A.G.; Yin, F.; Van Buijtenen, J.P. A hybrid engine concept for multi-fuel blended wing body. Aircr. Eng. Aerosp. Technol. 2014, 86, 483-493. [CrossRef]

10. Kawai, R. Benefit Potential for a Cost Efficient Dual Fuel Propulsion BWB. In Proceedings of the 51st AIAA Aerospace Sciences Meeting including the New Horizons Forum and Aerospace Exposition, Grapevine, TX, USA, 7-10 January 2013.

11. Nicotra, A. Bio-LNG is the sustainable fuel for Aviation. In Proceedings of the Kuala Lumpur 2012 World Gas Confererence, Kuala Lumpur, Malaysia, 4-8 June 2012; pp. 1-24.

12. Gti Energy. Available online: https://www.gti.energy/wp-content/uploads/2019/10/152-LNG19-03April2019Terpitz-Julian-presentation.pdf (accessed on 12 October 2020).

13. Gibbs, J.M.; Nagel, B. Design, economic competitiveness, and profitability of a 2025 LNG fueled turboprop for the LNG air transportation system. In Proceedings of the 54th AIAA Aerospace Sciences Meeting, San Diego, CA, USA, 2 January 2016; pp. 1-13. [CrossRef]

14. ZeroHedge. Available online: https://oilprice.com/Energy/Gas-Prices/Natural-Gas-Drops-To-25-YearLow-As-Demand-Disintegrates.html\#: \{\}:text=Natural\%20gas\%20prices\%20near\%20a,demand\%20and\% 20continued\%20LNG\%20weakness (accessed on 21 September 2020).

15. MANDATE E.U. M/400 to CEN “Gas quality": CEN BT WG 197 N 0310 Final Report. Available online: http://portailgroupe.afnor.fr/public_espacenormalisation/BNG234/FprEN16726\%20(E).pdf (accessed on 15 September 2020).

16. Berstad, D.; Nekså, P.; Anantharaman, R. Low-temperature $\mathrm{CO}_{2}$ Removal from Natural Gas. Energy Procedia 2012, 26, 41-48. [CrossRef]

17. Rufford, T.E.; Smart, S.; Watson, G.C.Y.; Graham, B.F.; Boxall, J.; Da Costa, J.D.; May, E.F. The removal of $\mathrm{CO}_{2}$ and $\mathrm{N}_{2}$ from natural gas: A review of conventional and emerging process technologies. J. Pet. Sci. Eng. 2012, 94-95, 123-154. [CrossRef]

18. Denys, F.; De Vries, W. The status of the transition to high-calorific-value gas. Gas Compos. Transit. Agency Rep. 2013. Available online: https://www.rvo.nl/sites/default/files/2013/12/New\%20Natural\%20Gas\%20Report $\%$ 202013\%20PNA.PDF (accessed on 15 September 2020).

19. ISO 6976:2016 Natural Gas—Calculation of Calorific Values, Density, Relative Density and Wobbe Indices from Composition. Available online: https://www.iso.org/standard/55842.html (accessed on 18 September 2020).

20. ISO 6578. Refrigerated Hydrocarbon Liquids-Static Measurement-Calculation Procedure. 1991. Available online: https://www.iso.org/obp/ui/\#iso:std:iso:6578:ed-2:v1:en (accessed on 18 September 2020).

21. Yin, F.; Grewe, V.; Fromming, C.; Yamashita, H. Impact on flight trajectory characteristics when avoiding the formation of persistent contrails for transatlantic flights. Transp. Res. Part D Transp. Environ. 2018, 65, 466-484. [CrossRef] 
22. Laskaridis, P. Performance Investigations and Systems Architectures for the More Electric Aircraft. Ph.D. Thesis, Cranfield University, Cranfield, UK, 2004.

23. Jenkinson, L.R.; Simpkin, P.; Rhodes, D. Civil Jet Aircraft Design, 1st ed.; Arnold: London, UK, 1999.

24. ESDU. Estimation of Airframe Drag by Summation of Components_Principles and Examples; ESDU-97016: London, UK, 1997.

25. Macmillan, W.L. Development of a Modular Type Computer Program for the Calculation of Gas Turbine Off-Design Performance. Ph.D. Thesis, Cranfield Institute of Technology, Cranfield, UK, 1974.

26. Nalianda, D.K.; Kyprianidis, K.G.; Sethi, V.; Singh, R. Techno-economic viability assessments of greener propulsion technology under potential environmental regulatory policy scenarios. Appl. Energy 2015, 157, 35-50. [CrossRef]

27. Wells, D.P.; Horvath, B.L.; McCullers, L.A. The Flight Optimization System Weight Estimation Method. Nasa/Tm-2017-219627. 2017. Available online: https:/ntrs.nasa.gov/archive/nasa/casi.ntrs.nasa.gov/ 20170005851.pdf (accessed on 12 October 2020).

28. Raymer, D.P. Aircraft Design: A Conceptual Approach, 5th ed.; AIAA Education Series; AIAA: Reston, VA, USA, 2012.

29. Roskam, J. Airplane Design: Part V, Component Weight Estimation; Roskam Aviation and Engineering Corporation: Ottawa, KS, USA, 1989.

30. Horvath, B.L.; Wells, D.P. Comparison of aircraft conceptual design weight estimation methods to the flight optimization system. AIAA Aerosp. Sci. Meet. 2018, 210059. [CrossRef]

31. Airbus. Available online: https://www.airbus.com/aircraft/support-services/airport-operations-andtechnical-data/aircraft-characteristics.html (accessed on 12 October 2020).

32. Boeing. Available online: https://www.boeing.com/commercial/airports/plan_manuals.page (accessed on 12 October 2020).

33. Mills, G.L.; Buchholtz, B.W.; Olsen, A. Design, fabrication and testing of a liquid hydrogen fuel tank for a long duration aircraft. AIP Conf. Proc. 2012, 1434, 773. [CrossRef]

34. NACA Research on Hydrogen for High-Altitude Aircraft. Available online: https://history.nasa.gov/SP-4404/ ch6-4.htm (accessed on 5 November 2019).

35. Sosounov, V.; Orlov, V. Experimental turbofan using liquid hydrogen and liquid natural gas as fuel. In Proceedings of the AIAA/SAE/ASME/ASEE 26th Joint Propulsion conference, Orlando, FL, USA, 16-18 July 1990.

36. Brewer, G.D.; Morris, R.E.; Lange, R.H. Study of the Application of Hydrogen Fuel to Long-Range Subsonic Transport Aircraft Volume 1. In NASA CR; 1975. Available online: https://ntrs.nasa.gov/citations/19790025036 (accessed on 12 March 2020).

37. Brewer, G.D. Hydrogen Aircraft Technology, 1st ed.; CRC Press: Boca Raton, FL, USA, 1991.

38. Winnefeld, C.; Kadyk, T.; Bensmann, B.; Krewer, U.; Hanke-Rauschenbach, R. Modelling and designing cryogenic hydrogen tanks for future aircraft applications. Energies 2018, 11, 105. [CrossRef]

39. Barron, R.F. Cryogenic Systems, 2nd ed.; Oxford University Press: New York, NY, USA, 1985.

40. Khandelwal, B.; Karakurt, A.; Sekaran, P.R.; Sethi, V.; Singh, R. Hydrogen powered aircraft: The future of air transport. Prog. Aerosp. Sci. 2013, 60, 45-59. [CrossRef]

41. Colozza, A.J. Hydrogen Storage for Aircraft Applications Overview; National Aeronautics and Space Administration: Cleveland, OH, USA, 2002.

42. Reynolds, T.W. Aircraft Fuel Tank Design for Liquid Hydrogen; National Advisory Committee for Aeronautics: Washington, DC, USA, 1955.

43. CFM56-7B: The Exclusive Boeing 737NG Engine. Available online: https://www.safran-aircraft-engines.com/ commercial-engines/single-aisle-commercial-jets/cfm56/cfm56-7b (accessed on 28 September 2020).

44. Boeing Commercial Airplanes Boeing 737 Airplane Characteristics for Airport Planning. 2020. Available online: https://www.boeing.com/resources/boeingdotcom/commercial/airports/acaps/737_RevA. pdf (accessed on 12 October 2020).

45. Torenbeek, E. Advanced AircraftDesign; A John Wiley \& Sons Ltd.: Chichester, UK, 2013.

46. Airbus. Liquid Hydrogen Fuelled Aircraft_System Analysis; Airbus: Toulouse, France, 2003. 
47. Rompokos, P.; Rolt, A.; Nalianda, D.; Isikveren, A.T.; Senné, C.; Grönstedt, T.; Abedi, H. Synergistic Technology Combinations for Future Commercial Aircraft Using Liquid Hydrogen. In Proceedings of the ASME 2020 International Mechanical Engineering Congress and Exposition GT2020 Virtual Conference, Online, 21-25 September 2020.

48. FAA. Design considerations for minimizing hazards caused by uncontained turbine engine and auxiliary power unit rotor failure. 1997; 20-128A. Available online: https://www.faa.gov/regulations_policies/advisory_ circulars/index.cfm/go/document.information/documentID/22187 (accessed on 17 October 2020).

49. Withers, M.R.; Malina, R.; Gilmore, C.K.; Gibbs, J.M.; Trigg, C.; Wolfe, P.J.; Trivedi, P.; Barrett, S.R.H. Economic and environmental assessment of liquefied natural gas as a supplemental aircraft fuel. Prog. Aerosp. Sci. 2014, 66, 17-36. [CrossRef]

Publisher's Note: MDPI stays neutral with regard to jurisdictional claims in published maps and institutional affiliations.

(C) 2020 by the authors. Licensee MDPI, Basel, Switzerland. This article is an open access article distributed under the terms and conditions of the Creative Commons Attribution (CC BY) license (http://creativecommons.org/licenses/by/4.0/). 